message recipients into users of a smoke alarm installation program occurred infrequently.

\section{DEVELOPMENT OF THE MAKE SAFE HAPPEN APP, A HOME SAFETY MOBILE APPLICATION}

1,2,3 Lara B McKenzie, ${ }^{1}$ Kristin J Roberts. 'Center for Injury Research and Policy, the Research Institute at Nationwide Children's Hospital; ' 2 Department of Paediatrics, the Ohio State University College of Medicine; ${ }^{3}$ Division of Epidemiology, the Ohio State University College of Public Health

\subsection{6/injuryprev-2016-042156.335}

Background Injuries are the leading cause of death for children ages $\leq 19$. Known effective countermeasures and safety devices are readily available, but not routinely utilised. Existing child safety efforts are not centralised or easily accessible and the current process for "child proofing" a home is difficult, confusing, and time-consuming. The objective was to development a home safety mobile application, to help parents and caregivers learn how to make their homes safer by identifying and remedying injury hazards in their home.

Methods The Make Safe Happen app allows users to identify injury hazards with room-by-room checklists and provides direct links to purchase safety products from an online, global retailer. In addition, app users can set reminders to help encourage correct and consistent use of these products. App users also had the option to complete a feedback survey embedded in the application. The app launched in February 2015 and is currently available for free from iTunes or Google Play.

Results As of October 2015, there were over 18,000 app downloads (iOS and Android). Over 20,000 safety actions (safety tasks completed by active app users) have been completed. In addition, 575 calendar reminders to check or change batteries and 502 poison control contacts (national poison control telephone number) have been created by app users. A total of 89 app users completed the survey. Of those, $86.5 \%$ reported that the app helped them to make their home safer, $75.6 \%$ learned something new, and $95.3 \%$ would recommend the app to a friend or family member. Additional analytic and survey data on the number of rooms completed and products purchased and installed will be presented.

Conclusions Parents and care givers want to protect and keep their children safe from injuries in and around the home. Preventing injuries helps ensure that all children and adolescents live to their full potential. The Make Safe Happen app was developed to bridge the information gap in a direct and efficient manner enabling the wider use of prevention measures that will protect children from injury.

\section{HARNESSING SOCIAL MEDIA FOR SAFETY}

Laura Hokkanen. Emergency Services College, Finland

\subsection{6/injuryprev-2016-042156.336}

Background Social media (SM) services are widely adapted by citizens, who at the same time are more and more equipped with mobile communication devices. As social networks have become common means for communication, also public authorities face the demand for being present online. How could the wide use of mobile SM be best harnessed for creating safety? This presentation addresses the use of SM and mobile technology in safety communication and communication during emergencies and crises.

Methods Presentation considers the issue through a literature review on research projects related to the utilisation of SM and mobile technology by public safety authorities. Reports of three EUFP7 funded projects and two Finnish Ministry of the Interior funded research projects are addressed.

Results $\mathrm{SM}$ is by nature multi-directional and interactive media. One-way, centralised communication has turned into communication of anyone and everyone. Easy access interaction between public authorities and citizens offers a new kind of forum for participating and sharing issues. Inviting citizens to take part in communication and involving them creates shared awareness and commits citizens in new ways - also in creating safety. Public safety authorities can also utilise mobile social media in fast distribution of information and gathering information useful for creating situational awareness. Questions such as the reliability of information, matters of privacy and data protection and the nature of the content published in SM need to be considered. Even a trusted institution needs to re-earn this trust when in SM. Conclusions Communication is a key factor in building resilience and promoting safety. New media provides a new kind of a forum - and a form - for interactive communication between public authorities and citizens that can provide benefits for both. The change in communications processes pose a challenge to safety organisations and utilising the new media requires skills and resources.

\section{SOCIAL MARKETING TO REDUCE PREVENTABLE INJURIES IN BC, CANADA}

1,2lan Pike, ${ }^{1,2}$ Shannon Piedt, ${ }^{2}$ Kevin Lafreniere. ${ }^{1}$ University of British Columbia, Canada and the BC Injury Research and Prevention Unit, Child and Family Research Institute, Canada; ${ }^{2}$ The Community Against Preventable Injuries, Canada

\subsection{6/injuryprev-2016-042156.337}

Background Well-developed social marketing campaigns can shift health-related societal attitudes and behaviours. The purpose of this study was to determine the efficacy of a social marketing campaign to raise awareness, change attitudes and behaviours to reduce the number and severity of injuries among citizens aged 25-54 in BC, Canada.

Methods A 2-year, 2-phase formative evaluation comprised focus groups and on-line survey. Phase I consisted 8 focus groups of 6-8 participants aged 25-54 throughout BC. The goal was to understand perceptions, attitudes, knowledge and behaviours, and to understand potentially effective injury prevention messages and channels. Phase II comprised on-line survey of 300 citizens 25-54 in May 2009. Demographic, knowledge, attitudes and behaviour variables around injuries served as pre-campaign baseline metrics. A multi-year, multi-faceted campaign, using TV, radio, print, signage, guerrilla events and social media launched in June 2009. Data from random samples $(n=700)$ were gathered at 4-month intervals and used to monitor changes in awareness, attitudes, behaviours, together with changes in injury deaths.

Results Some $50 \%$ of BC population (2M) were reached weekly, and over $100 \mathrm{M}$ media impressions were generated during the 6 month launch period. 50,000 visited http://www.preventable.ca. Campaign recall increased $45 \%$; TV ads were considered informative, relevant, credible and generated self-reflection with no advertising fatigue. Positive shifts (5-10\%) in attitudes and behaviours were observed, and significant differences persist over 7 - 